\title{
1
}

\section{History of childhood headaches}

\section{Andrew D. Hershey}

Headaches in children, adolescents and adults are quite common. The study and characterization of childhood headaches, however, entered an era of increased interest with the adoption of the first edition of the International Classification of Headache Disorders [1].

The initial description of headaches in humans is quite old. Ancient writings in an epic poem from the Sumerian area dating back to 3000 BC describe what appear to be migraine-type headaches (i.e. 'the sick headache').

The sick-eyed says not

"I am sick-eyed"

The sick-headed not

"I am sick-headed" [2]

The oldest known medical manuscript, a 3500-year-old papyrus found in the tomb of Thebes and translated by George Ebers in 1874 refers to 'a sickness of half the head' [3].

From the Mesopotamian literature, a migraine with aura appears to be described as: 'the head is bent with pain gripping his temples' and 'a man's brain contains fire and myalgia afflicts the temples and smites the eyes, his eyes are afflicted with dimness and cloudiness' $[4,5]$. Hippocrates in approximately $400 \mathrm{BC}$ also described what appears to be a migraine with aura that was relieved by emesis as 'a shining light ... followed by violent pain beginning in the temples and eventually reaching the entire head and neck area' [6-9].

Pediatric Headaches in Clinical Practice Andrew D. Hershey, Paul Winner, Marielle A. Kabbouche and Scott W. Powers (C) 2009 John Wiley \& Sons, Ltd. 
The specific discoverer of migraine, however, is often credited as Aretaeus of Cappadocia in the second century [10]. He described a mild, infrequent headache lasting a few days - cephalagia (i.e. tension headache); a longer, more severe and less responsive headache - cephalia; and a one-sided headache with blackness before the eyes, nausea, vomiting, photophobia and osmophobia - heterocrania (i.e. migraine) $[11,12]$. For the heterocrania he described a $6-24 \mathrm{~h}$ headache that could be on either side, front or vertical [12].

The term migraine (from the Greek hemicrania) appears to have been first introduced by Galen in the second century [3]. He described 'Hemicrania is a painful disorder affecting approximately one half of the head, either the right or the left side, and which extends along the length of the longitudinal suture .... It is caused by the ascent of vapours, either excessive in amount, or too hot, or too cold'.

The study of headaches from a modern, scientific point of view began in the 1700s. Tissot attempted to differentiate migraines from other headaches by describing them as a neuralgia provoked by reflexes from the stomach, gall bladder or uterus $[4,13]$. Fotherfill in 1778 provided a detailed description of a migraine attack is his paper 'Remarks on the complaint commonly known under the name of the Sick Headache' [3]. In 1873, Liveing gave a detailed description of megrim or sick headaches [14]. Many of the features he described in that paper continue to be recognized as clinical features today for migraine headaches.

\subsection{Childhood headaches}

Headaches in adults have been examined by many well-known neurologists. In children, however, the historical study of headache is much more limited. Tissot [13], Calmeil [15] and Living [14] referred to childhood headaches in their discussion of migraines [4]. This was limited to the observation that migraines may start in childhood. The initial description of childhood headaches themselves began to appear in the early 1900s [16-20]. These papers began to identify that children could suffer from the same headache disorders as adults, but with subtle variations.

One of the early theories on childhood migraines, as well as some adult migraines, was the possible causal relationship to allergy. Balyeat and Rinkel [18] in 1931 reported on their experience with migraine. They noted that $30 \%$ of their patients developed their symptoms before 10 years old. They 
related migraine to allergy based on the observation that many of the very young children came in with a complaint of allergies, but historical review revealed the presence of migraines. They also drew this conclusion based on the persistent family history of allergies and the presence of 'food allergies' (i.e. food triggers) presenting as cyclic vomiting. Ogden [21] in 1961, upon reviewing his studies, concluded that migraine and allergy may very well be related, but could not clearly define how. Stevenson [22] compiled much of this information in 1993 and concluded that the high frequency of both disorders contributed to this apparent relationship.

In 1949, Vahlquist and Hackzell [23] began a much more extensive study of childhood headaches. They reported their findings on 31 patients with onset of headache between age 1 and 4 years. This paper described patients that they had identified with migraine headaches. In doing so they began to develop criteria by which childhood migraines could be diagnosed. In contrast to the observations in adults, their study they noted a predominance of males [23], that children may have short-duration headaches, temperature may change during a headache, a psychogenic element is very important, and allergies or food sensitivities do not always bear out. One of the most significant features of this study and subsequent work was the initial establishment of criteria for the diagnosis of childhood headaches. These criteria described paroxysmal headaches that included two of four features: a pain occurring in only part of the head, the presence of nausea, the presence of a flimmer scotoma and a positive family history. Although these features do not meet the current criteria for diagnosis of migraines in adults or children, they did provide an initial framework for the study of childhood headaches. In 1955, Vahlquist in collaboration with Bille, Ekstrand and Hackzell used these initial criteria to screen 1236 school children between the ages of 10 and 12 years old for the presence of migraines [4]. They found the prevalence of migraines was $4.5 \%$, while the prevalence of nonmigrainous headaches was $13.3 \%$.

During the 1950s, several groups reported on their experience with childhood migraines and the features that may differentiate them from the adult migraine patients. Micheal and Williams [24] remarked in the 20 patients they followed that there was a significant association with seizure disorders. Krupp and Friedman [25] found that a large fraction of the 600 adults they studied had the onset of their migraines in childhood. They went on to characterize 50 children with migraines, finding that the headaches were quite similar to the adults they studied. The exceptions they noted were that these headaches were milder and had more significant gastrointestinal and psychological aspects. Glaser [26] reported his observations in 1954. He focused on the allergic 
component of childhood headaches, but did not conclude that there was a need to test for food allergies. He also noted that the onset may occur as early as infancy. In 1956, Burke and Peters [27] reported on their 6-year study of 92 patients, noting a higher incidence of migraines in childhood headaches than previously reported and a positive treatment response to aspirin, ergotamine/ caffeine, and diphenylhydantoin.

In 1962, Bille [4] expanded on this study in his very thorough work on headache in children. In the preface to this study, he discussed several historical observations about childhood headaches. These included that childhood attacks are more frequent, have a shorter duration with a shorter prodrome and have scotomas less frequently. In addition, the headache attacks appear to be less severe, have predominance of gastrointestinal symptoms, including cyclic vomiting and attacks of abdominal pain, and high fevers may be associated with headaches.

In Bille's study, he provided questionnaires to 9059 school children in Uppsala, Sweden, aged 7-15 years old attending school in 1955. It excluded children with mental handicaps or those who were attending vocational schools. The children and their parents were asked about the presence of headaches and, if headaches were present, they were asked to describe the features of the headaches. He received 8993 replies (99.3\%). The children were then divided into four groups: (1) children who never had a headache -3720 (41.1\%); (2) children with rare nonparoxysmal headaches - 4316 (48.0\%); (3) children with frequent nonparoxysmal headaches - 473 (5.3\%); and (4) children with paroxysmal headaches - 484 (5.4\%). He felt the last group represented the children with migraines. In this group, in addition to the headache being paroxysmal, he reported the most frequently cited features of these headaches were one-sided pain, nausea, visual aura, and a positive family history. From this study, he identified that approximately $25 \%$ of children reported a significant headache by age 5 years and that $75 \%$ of children had reported a significant headache by age 15 years. Within this age range they were able to suggest a frequency range for migraines from 1 to $7 \%$ dependent on age and sex. To assess the headache diagnosis more accurately, he contacted every fifth child in the 'migraine' group and every tenth child in the nonmigrainous paroxysmal group. He was then able to estimate the frequency of migraine to be $3.97 \%$ (357 out of 8993 ). He also characterized the lack of differences in these children compared with their headache-free counterparts in school performance, school attendance, or socioeconomics status. $\mathrm{He}$ further described the characteristics of these children and their headaches, including detailed features of the headaches, pediatric and neurological examinations, and electroencephalogram (EEG) examination. He has 
subsequently followed 73 children in the migraine group for up to 40 years [28]. Of these adults, $23 \%$ were migraine free by age 25 years; however, more than half continued to have migraines at age 50 years.

In 1976, Sillanpää [29] performed a similar study to Bille's. His study differed in that he questioned 4825 children aged 7 years old and found a prevalence of migraines at this age of $3.9 \%$. He used the Vahlquist criteria for the diagnosis of migraines and found that $37 \%$ of the children reported a headache of any type. In 1983, he described the results of a 7-year follow-up on 2915 of these children [30]. He found that in those 7 years the prevalence of headaches increased to $69 \%$ and the prevalence of migraines increased to $6.6 \%$ with the greatest increase occurring in girls (14.8\%). He also noted that this appeared to be a continuous trend of increasing frequency as the children advanced through adolescence.

In 1976, Prensky [31] reviewed the differences in children's migraines versus adult migraine. Some of the differences that he noted between children and adults were that there was a slight predominance of males ( $\sim 60 \%$ versus $\sim 33 \%$ ), less likelihood of unilateral headache (25-66\% versus 75-91\%), more nausea/vomiting (70-100\% versus 60-90\%), less visual aura (10-50\% versus $60-75 \%)$, and an increased incidence of seizures $(5.4-12.3 \%$ versus $<3 \%)$. He also noted that the familial incidence was approximately the same $(72 \%$ versus $71 \%)$.

In 1984, Barlow [32] published his book giving a descriptive account on childhood migraines. Much of this information is based on personal observations on 300 children with headaches over a 20 -year period. Through these observations, as well as a review of the literature, he focused on his experience with managing childhood headaches and the problems that arise. This included not only migraines, but also migraine variants, the periodic syndrome, psychogenic headaches, traumatic headaches, symptomatic headaches, and various treatment designs.

In 1994, Abu-Arefeh and Russell [33] reported a similar study to Bille's of 1962 using the International Headache Society (IHS) criteria. By using these criteria they identified that approximately $10.2 \%$ of children between the ages of 5 and 15 years met the IHS criteria for migraine headaches. Whether this implies a trend of an increasing frequency of migraine headaches or whether the use of the IHS criteria provides for more specific identification is unclear. However, the authors feel that the most likely explanation is the increasing frequency of headaches within a population. This is mirrored by studies in adults that agree with the increasing trend of the frequency of headaches. 


\subsection{Migraine variants and the periodic syndromes}

A unique feature in the childhood headache and migraine spectrum that has historically been noted is often referred to as periodic syndromes of childhood or migraine variants. Wyllie and Schlesinger described the periodic syndrome as having a combination of symptoms [34, 35], including one or more of:

1. cyclic vomiting of repeated bilious attacks;

2. recurrent vague abdominal complaints;

3. recurrent headaches;

4. dizzy spells;

5. periodic attacks of fever;

6. periodic attacks of limb and joint pains or stiffness.

In Prensky's review of migraine variants [31], he referred to these migraine variants as a 'recurrent syndrome'. He described this syndrome as 'recurrent abdominal pain with or without nausea and vomiting, cyclic vomiting, associated fever, and autonomic symptoms such as pallor and sweating as well as chest pains and leg cramps'. He reviewed 11 published series of such children, and although finding that $43 \%$ of these children had recurrent headaches, there were notable differences with the migraine group (less commonly male, more frequent seizures and paroxysmal discharges on EEG, more frequent history of seizures and less frequent history of migraines).

In Barlow's chapter on the periodic syndrome [32], he referred to Cullen and MacDonald's [36] conclusion that 'juvenile migraine is another nave for "periodic syndrome"'. He went on to review the literature and focus further on his experience with cyclic vomiting/recurrent episodic vomiting and 'abdominal migraine'/paroxysmal abdominal pain. He discussed several migraine variants that he had seen (including fever with migraine, paroxysmal leg pain and paroxysmal chest pain) that may be considered part of migraine variants or the periodic syndrome.

Other childhood variants of migraines have also been described. One of these is benign paroxysmal vertigo of childhood. Basser [37] originally described this in 1964 and Fenichel [38] related migraine as a cause for this in 1967. In a recent long-term follow-up, Lindskog et al. [39] reported that 13-20 years after the diagnosis of benign paroxysmal vertigo of childhood they were able to conclude that it is a benign illness that migraine may cause, but that migraine is not a general precursor. 
In 1969, Snyder [40] described a disorder of recurrent torticollis in infancy. Its exact etiology is unknown. Deonna [41] reviewed the possible association of this entity with migraines with the conclusion that so few patients have been accurately recorded that a direct relationship with migraine, although it may be possible, cannot be made for certain.

Another group of variants that have been described in children has been reviewed by Hosking [42] in which there is an alteration of consciousness or interaction with their environment. These include confusional migraine, the Alice in Wonderland syndrome, migraine stupor and transient global amnesia. Many of these unusual symptoms were described in children in the 1970s by various authors and are important to differentiate from other causes of acute alterations in consciousness.

\subsection{Classification and criteria for headaches}

Historically, the criteria for the diagnosis of childhood headache disorders relied predominantly on the clinician's impression. The Vahlquist criteria discussed above began to provide a basis by which childhood headaches could be studied and remained the central criteria for the study of childhood headaches and migraines. These criteria focused on the paroxysmal nature of migraine headaches in children with a few selective features (two of four features: a pain occurring in only part of the head, the presence of nausea, the presence of a flimmer scotoma and a positive family history).

During the same time period that Vahlquist and Bille were beginning to describe and classify childhood headaches, the Ad Hoc Committee on Classification of Headache suggested a classification scheme for headaches in adults [43]. This 1962 commentary suggested 15 different headache classifications, including 'vascular headache of migraine type', 'muscle-contraction headache' and 'combined headache'. Although this classification scheme differentiated headache types, it did not provide specific criteria for individual headache subtypes.

In 1979, Prensky and Sommer [44], based on a retrospective study of 84 children that had been clinically defined as having migraines, suggested refining the criteria for childhood headaches. Their criteria were:

1. recurrent headaches with symptom-free intervals;

2. three of six symptoms:

(a) abdominal pain, nausea or vomiting with the headache; 
(b) hemicrania;

(c) a throbbing, pulsatile quality of pain;

(d) complete relief after a brief period of rest;

(e) an aura, either visual, sensory or motor;

(f) a history of migraine headaches in one of more members of the immediate family.

In addition, they found 17 had paroxysmal discharges on EEG, a slight predominance of males (especially in children under 11 years), a predominant frontal location to the headache, and that about one-half of the children had a $50 \%$ reduction in their headache frequency independent of the treatment 6 months following a neurologist visit.

Although others have also suggested childhood headache criteria [45-48], no standardized criteria had been established. This left much of the reported studies of headaches, both in children and adults, to be based on an individual clinician's clinical diagnosis of headaches and migraines. In 1988, the IHS provided a major advancement in the further study of headaches when it published its initial IHS criteria. These criteria were developed by multiple headache researchers and used both clinical opinions and reported characterizations of individual headache types. In these criteria they established 12 different major headache types that could be roughly divided into primary headaches and secondary headaches. This work delineated detailed criteria for all headache types. These criteria also serve as the basis for the modern study of headaches in adults and children, with many of the observations and studies discussed throughout the remainder of the book using these criteria as a foundation for the scientific study of headache. The future will hold many new advances and discoveries for the treatment of childhood headaches are there, and the remaining chapters of this book will delineate our current understanding of childhood headaches.

\section{References}

1. Headache Classification Committee of the International Headache Society (1988) Classification and diagnostic criteria for headache disorders, cranial neuralgias and facial pain. Cephalalgia: An International Journal of Headache, 8(S7), 1-96.

2. Alvarez, W. (1945) Was there sick headache in 3000 B.C.? Gastroenterology, 5, 524.

3. Hanington, E. (1973) Migraine, Priory Press Limited, London. 
4. Bille, B.S. (1962) Migraine in school children. A study of the incidence and short-term prognosis, and a clinical, psychological and electroencephalographic comparison between children with migraine and matched controls. Acta Paediatrica (Oslo, Norway: 1992) Supplement, 136, 1-151.

5. Sigerist, H.E. (1951) A History of Medicine. Volume 1: Primitive and Archaic Medicine, Oxford University Press, New York, NY.

6. Silberstein, S.D., Lipton, R.B. and Goadsby, P.J. (1998) Headache in Clinical Practice, Isis Medical Media, Ltd, Oxford, UK.

7. Plato (1960) The Republic, in The Collected Dialogues of Plato (eds E. Hamilton and H. Cairns), Pantheon Books, New York, p. 103.

8. Lance, J.W. (1982) Mechanism and Management of Headache, 4th edn, Butterworth Scientific, London.

9. Edmeads, J. (1990) The treatment of headache: a historical perspective, in Drug Therapy for Headache (ed. R.M. Gallagher), Marcel Dekker, Inc., New York, pp. 1-8.

10. Waters, W.E. (1986) Headache, Series in Clinical Epidemiology, PSG Publishing Company, Inc., Littleton, MA.

11. Critchley, M. (1967) Migraine: from Cappadocia to Queen Square, in Background to Migraine: First Migraine Symposium (ed. R. Smith), Heinemann, London, pp. 22-38.

12. Rose, F.C. (1995) The history of migraine from Mesopotamian to Medieval times. Cephalalgia: An International Journal of Headache, S15, 1-3.

13. Tissot, S.-A. (1783) Traité des nerfs et de leurs maladies. De le catalepsie, de l'exstase, de l'andesthésie de la migraine et des maladies du cerveau, in Oeuvres de Monsieur Tissot, P. F. Didot le jeune, Paris.

14. Liveing, E. (1873) On Megrim, Sick-Headache, and Some Allied Disorders: A Contribution to the Pathology of Nerve-Storms, J. and A. Churchill, London.

15. Calmeil, H. (1832-1846) Migraine, in Dictionnaire de Médecine (ed. N.P. Adelon), Béchet jeune, Paris.

16. Comby, J. (1921) La migraine chez les enfants. Arch de Médec des Enfants, 24, 29-49.

17. Curschmann, H., (1922) ber Kindemigräne. Münchener Medizinische Wochenschrift, 69, 1746.

18. Balyeat, R.M. and Rinkel, H.J. (1931) Allergic migraine in children. American Journal of Diseases of Children, 42, 1126-1133.

19. Debre, R. and Broca, R. (1935) La migraine chez l'enfant et son équivalent abdominal. Le Bulletin Medical, 49, 467-477.

20. Riley, H.A., (1937) Migraine in children and the mechanism of the attack. Bulletin of the Neurological Institute of New York, 6, 387.

21. Ogden, H.D. (1961) The relationship of allergy to headache. Headache, 1, 14-19.

22. Stevenson, D.D. (1993) Allergy, atopy, nasal disease, and headache, in Wolff s Headache and Other Head Pain, 6th edn (eds D.J. Dalessio and S.D. Siberstein), Oxford University Press, Oxford, pp. 291-333.

23. Vahlquist, B. and Hackzell, G. (1949) Migraine of early onset. A study of thirty one cases in which the disease first appeared between one and four years of age. Acta Paediatrica, 38, 622-636. 
24. Micheal, M.I. and Williams, J.M. (1952) Migraine in children. The Journal of Pediatrics, 41, 18-24.

25. Krupp, G.R. and Friedman, A.P. (1953) Migraine in children. American Journal of Diseases of Children, 85, 146-150.

26. Glaser, J. (1954) Migraine in pediatric practice: observations with special reference to migraine of allergic origin. American Journal of Diseases of Children, 88, 92-98.

27. Burke, E.C. and Peters, G.A. (1956) Migraine in childhood: a preliminary report. American Journal of Diseases of Children, 92, 330-336.

28. Bille, B. (1997) A 40-year follow-up of school children with migraine. Cephalalgia: An International Journal of Headache, 17, 488-491.

29. Sillanpää, M. (1976) Prevalence of migraine and other headache in Finnish children starting school. Headache, 15, 288-290.

30. Sillanpää, M. (1983) Changes in the prevalence of migraine and other headaches during the first seven school years. Headache, 23, 15-19.

31. Prensky, A.L. (1976) Migraine and migrainous variants in pediatric patients. Pediatric Clinics of North America, 23(3), 461-471.

32. Barlow, C.F. (1984) Headaches and Migraine in Childhood, Spastics International Medical Publications, London.

33. Abu-Arafeh, I. and Russell, G. (1994) Prevalence of headache and migraine in schoolchildren. British Medical Journal, 309, 765-769.

34. Wyllie, W.G. and Schlesinger, B., (1933) The periodic group of disorders in childhood. British Journal of Children's Diseases, 30, 349-351.

35. Silberstein, S.D. and Saper, J.R. (1993) Migraine: diagnosis and treatment, in Wolff's Headache and Other Head Pain, 6th edn, (eds D.J. Dalessio and S.D. Siberstein), Oxford University Press, Oxford, pp. 96-170.

36. Cullen, K.J. and MacDonald, W.B. (1963) The periodic syndrome: it's nature and prevalence. Medical Journal of Australia, 50, 167-173.

37. Basser, L.S. (1964) Benign paroxysmal vertigo of childhood. Brain: A Journal of Neurology, 87, 141-152.

38. Fenichel, G.M. (1967) Migraine as a cause of benign paroxysmal vertigo of childhood. The Journal of Pediatrics, 71, 114-115.

39. Lindskog, U., Odkvist, L., Noaksson, L. and Wallquist, J. (1999) Benign paroxysmal vertigo in childhood: a long-term follow-up. Headache, 39, 33-37.

40. Snyder, C.H. (1969) Paroxysmal torticollis in infancy: a possible form of labyrinthitis. American Journal of Diseases of Children, 117, 458-460.

41. Deonna, T.W. (1988) Paroxysmal disorders which may be migraine or may be confused with it, in Migraine in Childhood (ed. J.M. Hockaday), Butterworths, London, pp. 75-87.

42. Hosking, G. (1988) Special forms: variants of migraine in childhood, in Migraine in Childhood, (ed. J.M. Hockaday), Butterworths, London, pp. 35-53.

43. Friedman, A.P., Finley, K.H. et al. (1962) Classification of headache: Ad Hoc Committee on Classification of Headache. The Journal of the American Medical Association, 179(9), $127-128$. 
44. Prensky, A.L. and Sommer, D. (1979) Diagnosis and treatment of migraine in children. Neurology, 29, 506-510.

45. Deubner, D.C. (1977) An epidemiologic study of migraine and headache in 10-20 year olds. Headache, 17, 173-180.

46. Congdon, P.J. and Forsythe, W.I., (1979) Migraine in childhood: a study of 300 children. Developmental Medicine and Child Neurology, 21, 209-216.

47. Jay, G.W. and Tomasi, L.G. (1981) Pediatric headaches: a one year retrospective analysis. Headache, 21, 5-9.

48. Kurtz, A., Dilling, D., Blau, J.N. and Peckman, C. (1984) Migraine in children: findings from the national child development study, in Progress in Migraine Research, 2 (ed. F.C. Rose), Pittman Books, London, pp. 9-17. 
